$\infty$
0
0
0
0
0
0

James A. Levin

Neil M. Goldman
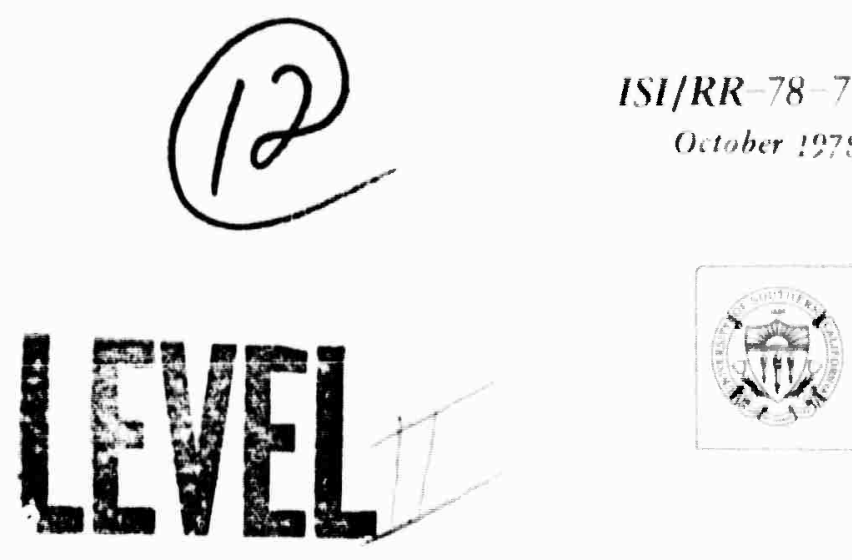

\title{
Process Models of Reference in Context
}

恼

岸

它


INFORMATION SCIENCES INSTITUTE






\section{BEST \\ AVAILABLE COPY}


REPORT DOCUMENTATION PAGE

READ INSTRUCTIONS MFORE COMPLETING FORM

ISI/RR-78-72

Process Models of Reference in Context. ECIPIENT'S CATALOG NUMBEA 8 : GOVT ACCESSION NO. 7.

1

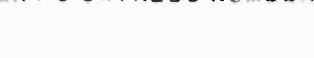
Neil M. Goldman

9 PERFoRMING CRGANIZATION NAME AND ADORESS

Information Sciences Institute

4676 Admiralty Way

Marina del Rey, CA 90291

11 CON THOLLING OFFICE NAME AND ADOAESS

Mathematical and Computer Sciences Division

National Science Foundation

1800 G St. NW Washington, D. C. 20550

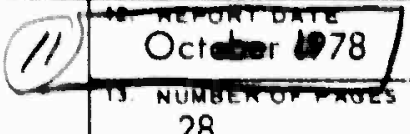

Research



1. MONITORING AGENCY NAME A AODRESS(ll dillerent from Controlfind Officol

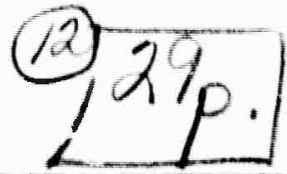

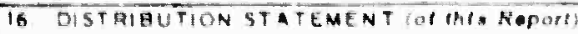

This document approved for public release and sale; distribution is unlimited.

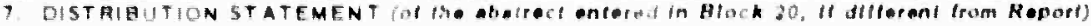

13 SUPPLEMENTARY NOTES

James Levin is now located at the Communications Program, University of

California at San Diego, La Jolla, CA 92093.

19. KEY WOROS (Continue on reverse alde II neceeceary and ldertlly by hlock number)

anaphoric reference, artificial intelligence, context models, natural language generation, natural language processing

20) ABStract (Continue on reverae elde Il naceceany end ldantity by block number)

Reference is a central issue for language comprehension and generation. After reviewing existing process models for comprehending and generating referring expressions, we present a general framework for context and reference processing. The context for reference processing is represented as a "Public Workspace. "." Reference processes access Public Workspace and modify its content, which is the set of concepts currently Yon the table $e^{\text {se }}$ as far as the current language interaction is concerned.

(OVER) 
20. (continued)

Information from many different sources can be integrated in comprehending or generating referring expressions. Within this general fromework, o new system for selectively generating referring phrases is developed. This system decides how much to express about a given concept in a given context.

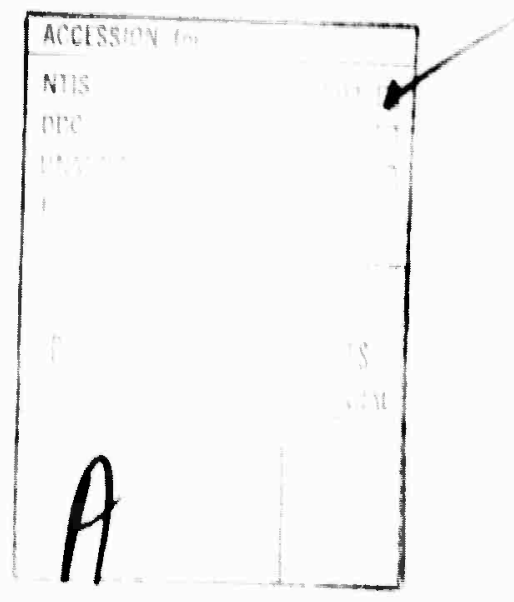


$|S| / K K+8$

(1.6) 1978



James A. Levin

Neil M. Goldnan

\section{Process Models of Reference in Context}

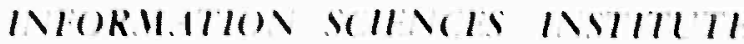




\section{CONTENTS}

Abstract $\vee$

Introduction 1

The Representation of Context for Reference Processing 2

Syntax-Dom Inated Context Representations 3

Semantic-Dominated Context Representations 3

Psychological Evidence about Human Context 3

Multilevel Representations 4

Properiles of Context for Reference Processing 4

Public Workspace 4

The Use of Context in Reference Processing 6

Rcference Processes in Existing Systems 6

Classification of the Reference Heuristics 8

A General Framework for Reference Comprehension $\|$

F.llipsis 12

Heference and Generation 14

Existing Reference Generation Models 15

A System for the Selective Generation of Referring Phrases 17

What To Say 17

Summary 21

Meferences 23 


\section{AlSS'RAC'T}

II. Ierence is a central issuc for languafe comprchension and generation. After revinwinf, existing, process nodels for comprehending and generating referring expressions, we present a general framework for context and reference processing. The context for reference processinf is represented as a "Public Workspace." Muference processes access I'ublic Workspace and modify its content, which is the sit of concepts cuirently "on the table" as far as the current language interaction is concerned. Information from nany different sources can be integrated in comprehending. or generating, referring expressions. Within this general Iranicwork, a new system for selertively generating referring phrases is developed. This system decides how much to express about a given concept in a given context. 


\section{INTRODUCTION}

Wilton Times. W.Va.: "The bad news didn't surprise Miss P.nkrom, who is expccting a baby. She said she had been half expecting it."

II Is clcar that context plays a critical role in the comprehension and grneration of language. By ttsclf, the word "it" has little meaning--only in a particular context does it have a referent. Aithough the importance of context is obvlous, models of language processing have not dealt with context in a satlsfactory way.

We will discuss some recent process models of the comprehension and the cennration of referring phrases. First, we will look at the various representations of context that have been proposed, then we will cover the various ways in which context has been used in the processing of referring phrases, and finally, we will present a model that decides how much to include in the referring phrase generated for a given corcept. 


\section{THI REPRESENTATION OF CONTEXT FOR REFERENCE PROCESSING}

Ihllosophers of lanfuafe, linguists, psychologists studying language, and computer sclentlsts bullding language processing, systems have untll recently avolded context 1ssues. One reason has been the lack of good representatlons of context. We will look at some of the process models of language that have used context to deal with referring expressions and then examine some of the psychological evidence of the structure of context in human language processing. Usinf, some of the notions contained in recent representational formats developed in ortificlal intellifence, we will describe a llew proposal for representing context for reference processing.

We are presuming a view of communication in willch scquences of words, refering phrases, are assoclated in the minds of the speaker and llstener with referent concpes. These referent concepts are often also associated in their minds with particular objects and events in the world of discourse, called the ieferent etfects of the phrases. Plirases having, a common referent concept are called co-referental.

Lanfunfe comprehension requires the discovery of referent concepts for referrinf. phrases, wherens latellage feucration requires the production of refertur. phrases for referent concepts. The notion of reference is best exemplified by referring. phrases which are syutactically noun phrases or pronouns, and by referent concepts which represent concrete individual objects or sets of such objects. llowever, referrinf, phrases may come in other syntactle forms, and referent concepts may represent events and ahstract concepts as well as concrete olijects.

Birference, as we are viewing, it, is a procedural notion spectfic to lndividual process models; one cannot, in fencral, sposk meaningfully of the concet referent concept of a fiven plirase. To illustiate this consider: "I took the paint of the shelf and opened 1t." (Ine model may decide, say by syutactic ninans, that the referent of "it" Is the alnt and then, considering the semantics of "open," decide that what was opened was not the paint itselt, but its contatner. A second nodel may operate by lookinf. through its context for a "ficuderless individual" object which can be operled, and find the can of paint as the referent concept of "it." The two models have come to the same Interpretation of the selltence, but by different paths. We are distingulshinf. the question of "what was opened," which relates only to the information content of the sentence, from the question of "what is the referent 
concept of 'it'," which may have different answers for different processes independent of how they answer the tirst question.

\section{SYNTAX-DOMINATHD CONTEXT REPRESENTATIONS}

Though it remains oue of the landmark systems for processing natiral linf.uare. Blocksworld (Winof,rud, 1972) had a relatively simple notion of context cmbedded wlthin it. For comprohending and gencrating, referring phrases, pirticularly pronoums, it relicd hesvily on scarches through the parse trees of the previnus utterances. Information atrout this symtactic position of previously occurrinf, referring. phrases stored in these parse trecs was used by Blocksworld to fird the referent of a referrinf: phrase. This context was dynamic, in the serse that ouly the few most recent parse trees were searched.

\section{SFMANTIC-DOMINATED CONTEXT REPRESENTATIONS}

Another approach to reference processing, was taken by the MARGle system (Hinger, 1975). In this system, the comprehonsion of a referring phrase was deferred by the parsing systen, and was attempted instead by a later inferencing system. As a context within which to pocess the reference, MARGIE used its memory of "conceptual dependencies." None of the syntactic Information about the place of the current expression in the imput uticrance nor syntactic information atout previous expressions was used by the inferencing, part of MARGIE. Also, its context was monotonically frowing. modified only hy addition of conceptual dependency structure derived from the comprehension of successive input ullorances.

Siveral langusace comprehension models have introduced information sthemas which amalfamate knowledge about a central concept (Schank \& Abelson. 1975: nobrow \& Winofrad, 1977; llayes, 1977). (nce these models have determined that the central concept has been referenced, the entire schema forms a context which makes related concepts available for instantiation. One purpose of this is to focus the scarch for referent concepts of expressions seen later.

\section{I'SYCIIOIOCICAI. EVIDENCE. ABOUT HUMAN CONTEXT}

The notion of context that we have been exploring corresponds roughly to the psycholofical notion of "short-term memory." $\Lambda$ s the name implies, humans have a memory for events, which foes away after a whlle. Numerous experiments hive investifated the nature of this memory using nonsense syllables, but few have used naturally occurring, languasc, largely because of a lack of an adequate representation for language as a stimulus material. However, in experiments with nonsense syllables, short-term memory has been found to be limtted (Miller, 1956) but hicrarchically structured (Mandler, 1968). 


\section{MIIITIIFVEI, RFIRFSENTATIONS}

Conststent whth these findings of herarchical structure in short-term incillory, several recent representational formats have incorporated the notion of IIIItilevel descriptions of concepts. 'The Mtill.IN system (Moore \& Newell, 1973) and liter the KHI, system (Hotirow \& Winoprad, 1977) are representational formats thint allow concepts to be represented at inany different levels of specificity.

Fl Pase 7iries, Texas: "The monager of a nudist park coinplains that a hole was cut in the wall surrounding the camip. Police are looking into II."

The need for multiple levels of description in reference processing is illustrated by this quotation. Let us cousider the issue of determintug the referent cencept for "It." The humor cones from the incongruity of the interpretations that: 1) the poltce are looking, into the nudist park, or 2) the poltce are looking into the hole, or 3) the poltec are looking. into the wall. However, note that even when tlinse inconfirunus interpretations are ruled out, there remain two distinct


looklilf into the culting of a hole. We are not limmedlately aware of this "Imblfiulty" berause it doesn't really naske much difference for the overall Interpretation of the sentence. At some level, these two low-level differences in literpretation are covered by a conmou higher level description.

\section{PROIERTIES OF CONTFXT FOR RFFFRENCE HROCESSINC,}

To summarize the discussion so far, context for reference processing requires the followinf, propertics:
1) It is derived from the languype beinf, processed,
2) Il draws upon permancnt knowledge,
3) llistrauslent.
1) Il is structured,
b) it permits nultiple levels of description.

\section{PUIIIC WORKSPACE}

Given these destderata, we have developed a representation for context that is derived from a previous notion of "Workspace" (Levin, 1976) as a kind of structured dynamic short-term memory containins "actlvations" of permanent 
"concepts" and relationships between them in long-term memory. Fach activation In the Workspace has a numerical salience value: when the salieice of a given activation falls below a flobal threshold level, the activation disappears from the Workspacr.

"l'ublic Workspace" is a subset of tlin overall Workspace, containing only these actututions derived from the processing of ulterances in the current interaction. In a di.lof,uc, for example, the liublic Workspace of a participant collains activations of those roncepts and relationships "on : tac table" as far as the current state of the dialogille !s concerned. Sunce each purtfelpaut knows that the other purtlclpant is currenly aware of these concepts, cach participant can rely upon this shared awireness in processull, referrin! phrases. This lublic Workspace represchtation is similar functionally to (hate's "foreg,round" notion (Chafe, 1974). 


\section{THE USE: OF CONTEXT IN REFERENCE PROCESSING}

So tar, we have restricicd our discussion or context solely to the representation tssucs. We are also interested in the kinds of processes this! use context to deal with referrinf phrases. In this sectlor, we will re-examine some natural ! aruare systems, lookinf, at the kinds of processes they use, and we will classify incse processes into iwo major calcfories, which we will relate to our lublic Workspace representation of context.

The alforithns used for reference determination are examples of the fenrate-and-test paradigm. liverse sorts of information are fenerally avallable for findinf, a referent--syntactic clues, discourse clues, worki knowledge--and the alfortithms typtcally use certain so:ts of ingormation to genetwe possible referent concepts and other sorts of information as filters to test the plausibility of the hypothestzed referent concepts.

\section{MFFFR FCE PROC.FSSES IN EXISTING SYSTFMIS}

\section{Hefricure in Illoch oworld}

Winof,rad (Isia) Implemented heuristics for reference resolution which wire alie to drill with two modes of reference to the objects in his llocksworld: reference by partial description and reference by prounoun. For Fittin descriptions, a list of all hocks that had the propertles spectfied th the description was collected. If the size of this sef was appropriate for the quantifiers, quiltiers, and determthers in the description, the sit of objects found was used as the refereut. If tow mony were found, an aftempt was minde to restrict the stet to those most recently teferenced. If too few were found, the descriptlon was reparsed if possible. As a lost resnt, the systell asked for more informatlon

The process fincrated possible referents for the pronoun "lt" uot hy usher lts simintic model. hut by aplyinf. rule hased on syntactic criteria for finding: platsibleco-referentialexpressions in the preceding dialog.te. The semantic model of the llocksworld was used to fultur out possible referents, and the syntactically most plausible referent concept which passed the semantic filter was accepted. 


\section{Heference in MARCit:}

Some systcms find the referent concepts for expressions solely on the basis of s'lliantic Icatures, irnoring, syntactic features. Gulllian (1969) described surh a syste'll, and Hiefer (1975) used a similar approach to find the referent concepts for definite noun phrases within :he Mnligle System (Schank, Goldman, Rieger, ke lilinilick, 1973).

In lieger's approach, a referring, expression contributes specifications which thin referent concept must sitisfy. A search is conducted to find all concepts in Inrillory which are compatible with the specifications. Because the comprehension systrin ned not have the sane knowledye atout the discourse objects as the sp'aker has, this compatibility test illvolves a partial match prucess, which contributes a score indicatinf, how well all object matches specifications. In midition, lliefer maintained for ench concept two attributes which aided in roference resolution. Ilt:CENCY, which fulicated when the concept last served as the referent concept of some linguistic structure, and TOUCHFi), which indicated whrn the concept was last accessed in reasonill, proresses. The reference finder IIsed 4 se attributes to defille an illplicit noiion of salience, which was used to hipip r'solve references which the partial match process failed to resolve.

In addition, linger's model was able to use its inference capalilities to find specifications not derivable from the referring, expression itself. There were two sources of such specifications:

- Any are "ment of any predicatc could have a "specificr program" associated with It. "his was a program which could add new spcrifications for the arpument dssociated with it, contingent on context and on existing specifications for the various arguments of the predicate.

- The fiencial inference mechanism was designed so that it could work with predications mixinf particular concepts and described concepts (sets of specifications). When the specifications from the referring expression, tog, nther with those added by any applicable specifier program, were insufficient to uniquely identify a ceferent, those specifications, plus any other features common to all remaining candidate referent concepts, formed a temporary concept. The inference rules were then permitted to operate as thouph this concept were a valid referent. The inference rules might then add further specifications to this concept and eventually narrow the sct of candidate referent concepts. If inference processe: halted without identifying a definite referent, the temporary concept could be carried along until additional text was processed. In theory, only the need to produce some form of external behavior could force the model to decide on a referent. 


\section{C:IASSIFICATION OF TIE RIFERENCE IIEURISTICS}

lint us look at some reference heuristics, including those we have discussed already, plus additional ones described in papers by Warnock (1972) and laranofsky (1970).

We can classify them into two categories: those dealing, with the possible refcrent concepts and those dealinf.. 'h the referring, cxpression.

The heuristics that deal with aspects of the possible referent concepts are a diverse lot, covering, both syntax and semantics. One thinf, secms to be a common friture--each scems to reflect contributions to the salience of the various concepts in awareness. Some of the heuristics capture what is called "focus"; others reflect the fact that concepts in awareness are temporary, disappearing if they aren't refreshed.

1. I'roximity: The closer an expression is to the referring, expression, the more likrly it is to br co-referential with the referring, expression. That is, the more recrilly a concrpt has been relerenced, the more likely it is that the concept is aptain being, relerencrd.

"I con't find ally documentation on the prof,ram. I have a tape here at Purdue and 1 can't fif.ure out what format it's in."

The "it" refers to the tape, not to the documentation or to the program.

2. Syntactic role in the sentence:

2a. Subject/Ob.ject/l'reposition phrases: The referent concept of thr syntactic subject of an utterance is more likcly to be re-referenced than ts the referent concept of syntactic ohjict, which is itsclf more likely than the referent concept of a prepositional phrase.

"O: The output comes out on the line printer.

l.: Throw it away..."

The "It" refers to the output (the syutactic subject of the first utterance) rather than to the line printer (the syntactic object).

2b. Superordinate/subordinate: Concepts referenced in a superordinate clause are more likely to be re-referenced than those in any subordinate clauses.

"... the tnpe that file is archived on scems to be a bad tape. We can't seem to get it to rend ..."

The "it" refers to the tape rather than to the file (in the subordinate relative clause).

2.c. Topicalization: Some special syntactic constructions (such as cleft 
sentences) can be used to emphasize one element of an utterance. The referent concepts of cniphasized expressions are more likely to be re-referenced than those of unemphasized ones.

"... there is a background job running here that checks to see if there is

ally unsent mail. Once it finds some, it tries to resend tt,"

The two "it"s are co-referential with the topicalized "background Job" rather than with the "unsent mail."

3. Centrality: The more frequently a concept has been referenced the more likely It is to be referenced apain.

"l.: ... Any chance 1 can recover [file name] from the most recent system dump?

(o: l'robably, let me look for it and get back to you, ok?

1.: Could you SNIIMSG to me, one way or the other? 1 won't be doing anything ahout it tonight. If it is there, I will be forever grateful to recover it."

The "it"s by 1 , all refer back to Lis file, rather than to the system dump or the one way or the other.

1. Current topic: $n$ n expression which refers to a concept in the current topic is more $11 \mathrm{kcly}$ to be co-referential. Dewtsch (19'(1) observed that definite references can norinally be minde only to concepts that are part of a currently "open topic." Guce a topic is "closed," It must be reopened before concepts within it can be referenced afiain.

"L: ... Can you recover those files for me..as far as I know they were in the directory on the 16 th. .. the names are...

\section{[ intervening, dialogue ]}

O: OK I have found the files you want. I will retrieve those for you ..."

In the second utterance, $O$ initially specified the files in some detall, but once the topic was re-cstablished, Just "those" sufficed.

There are also heuristics that supply information about what the referent of the referrinf expression can be. These heuristics focus on the information content of the cxpression and its immediate context.

1. Specification within the referrinf, expression:

1a. The pronoun in an expression of tell specifies that the referent concept be a particular number and/or f,ender.

"How do / fiet Hunoff to work?"

Thr pronoun "l" completely : pccifies the referent concept to be the speaker.

1h. The head noun of the referring expression frequently names a class of oljects or events; the referent concept nust be an individual within that class. 
"I have found the files..."

1c. The othet nodifiers in the referring, expression, such as adfectlves, relative clnusces, prepositional phrases, and possessives, often further specify the referout.

"I have found the flles you ale onemed atout..."

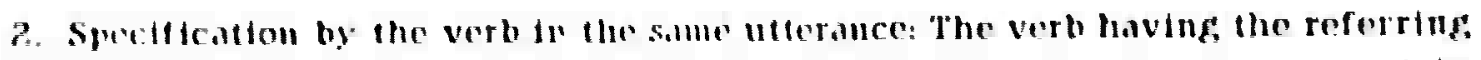
cxpresston as an amument of ten spetfos that the referent concept have certatn moperties.

"lhrow it awdy."

The verh (and viph pittele) "throw awey" spectes the referent to be something of matlo vilue to the singket.

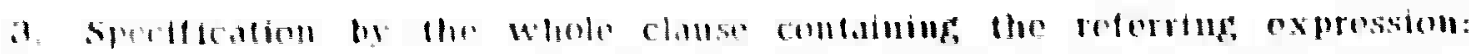


ronstrithts on the referent.

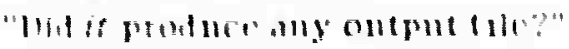

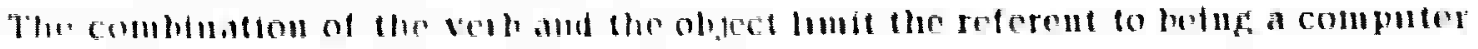
proptrin of some kind. 


\section{A GIINIIRAI, FRAMIIWORK FOR RF,FIRI:NCI: COMPIRFIIENSION}

'Ihe classification of the reference heuristics tinto these two categories silysests a feneral appronch toward modelluf, reference abilitics in process modeis. There should be two purts of such a model: the processes that contribute spureftications to the referent concept of thr current expression, and the processes thist affect the s.lfence of all the other currently active concepts. Given a spreadinf, actlvation processinf, tramework (Collins \& loftus, 1975: l,cvin, 1976; l,evin, 1978), we cin integ,rate all of the information supplind by the heuristics collcerninf, aspects of possible referent concepts by having, each such process modify the salience levels of the activations in the Public Workspace. Since these chimg!es are f.lobal, the resultant s.lience values are thus th $\mathrm{c}$ integrated result of all thr currently active processes. These sellience values can iken be used to resolve amhifuous cases, in a way analogous to but more general than the plausibility riting:s used by previous systems. With this mechantsm, any additional fillormation sources call be added casily by havint: them modify the salfence of activations in the lublic Workspace, concurrently with the processes aiready Imiplenented.

Initially, the reterent concent of all cxpression is completely unspecified. linth of the hruristics concerming the roferring expression can be seen as colltributinf, specifications to this unspecilied concept. Hach heuristic may operate Iuirpendently in addinf, its constraints to the referent of the current expression. 'The chd result is the partlally spccificd reterent. 


\section{liLIIISIS}

An issue closely related to reference determination is that of ellipsis, a surface furm which omits the specificition of crrtain syulactic or srmantic roles. Most models of lanfuafe comprehension attempt to "recover" onitted material in at least some situntions, that is, to fiud the referent concept of au "empty" expression.

$A$ lingulstic approach to this problem is to vicw ollipsis as the result of d. Irtion rules in a fiammar, and to recover the omitted concept hy reconstructlug. the parse tree from which the diletion was inade. The result is to determine that the cmpty expression is co-referelltal with some expression oppearing, in the surface structure, to which the normal rules for reference determination can allily.

The frammar-based approach offers no solution to many forms of ellipsts, buwever. For instance, It cannot determine the missing object of "fired" In

The soldier picked up his rifle. lie fired (empty).

$A$ straightforward approach to smdur. the referent in such a case is to treat (cimply) as a mumberless, fonderless pronoun and apply available rules for finding the referent concepts of pronouns. It is uot clear, thoush, when frammatical rules Ior pronouns can be extended to omitied arfuments, or to what extent the observed phobublittes for locations of antecedents extend to cases of ellipsis.

Oine reason that process models attempt to find or create referent concepts for omitted material is that these reforent concepts may themselves be the referent concepts of expressions appearing, later in a text:

The soldier took careful aim and fired.

The rifle's recoil knocked him down.

Both the proxtmity and syulactic role rules are enhanced by the recovery of oultted arfuments.

It has also hern noted that once a concept has been referenced, certaln concepts prediclably assoclated with that concept can serve as referent concepts of later expressions without any explicitly mentioned link to the flist concept. This form of reference has been handled, at leust in some cases, by the introduction of knowledge schemas, as previously described. When a text presents sufficient 
cuidence to "instantiate" one of these units, varlous concepts within the Instantlation become avallable as potential roferent concepts, even though they have never becn cxpltclly nientioned in the text. Using a "script" about restaurants, SAM (Schank, 1975) can proccss:

John went to a restaurant. The hostess seated John.

and Interpret It In a way that connects tho referent concepts of "restaurant" and "hostess" In a rational manner. 


\section{RLIFRENCE AND GENERATION}

In comparison with the larfe investment in process models of language compuchension, little study has been devoted to the process of language generation. This is particularly true with respect to reference. The reference problem for a ficherator can be stated as

Given the foal of expressing, something, about a concept $C$ in a particular context, how should $C$ be referred to? That is, what subset of the information known about $\mathrm{C}$ should be expressed and how should th be expressed?

It is possible to fencrate phrases to refer to concepts of all sorts: specific physical chjects, events, alıstract qualitics, fencric objects, sets, predicates, etc. The natural languse ficnerator has two orthofonal concerns. It must determine what information to convey about the concept, and it must select the words and syntactic forms appropriate to carry ollt the erference. The cholce of information does not necessarily dictate the words and syutax:

I s.iw the find and citery collide.

l suw the collision betwern the ford and the cheyy.

Nor does a choice of syntix necessarily dictate words or information content.

I silw the colleston betuech the ford and the cheyy.

I saw tlir auromontle crash.

The frenretor not olly must produce frammatical referring phrases for Individual concepts, but must maintain frammaticality when those phiases are rombined. Certain choices mny constrain others. For example. "I assume the ford and Chevy collided" is f,rammatical, while "I assume the collision between the Ford and Chevy" is not.

In fincrafine, a referrinf, expression, a fencrator may make use of the previously descrited aspects of such expressions: explicit specifications within the plirase, specificitions implicit in the syutactic role played by the phrase with respect to a verh, and specifications implicit in a whole clause. This means that the fineritor may be alle to make tradeolfs within a sentence; the selection of a pirticular vert or the inclusion of cortain specifications in one referring expression may affect the information content necds of another reference. 
It is posstble tar a verb or phrase to colltribute implicit specifications to a precedinf. phrase, so a strictly left-to-rigilit felleration stratefy cannot account for seline reasoliable reterellces. Collsider, for example, the common form of solitaire in which a lefal move consists of placing, a card onto another card of opposite color. In a situation with one kinf, and one quren of ench color available, the statement "l'lace the quecen on the king" is ambirfuous, whereas both "llace the red queen on the kinf:" and "l'lice the queen on the hack kinf" unambifiously specify the same move.

\section{FIISTINC, RFFERINCF GENIRATION MIOIIIS}

Two feneration models (Simmons \& Slocum, 1972, fioldman, 1976 ) addressed only the lssue of how to express as an linglish strims the information that they wire fiven. loth prestumed that no information selection was required. llocksworld (Winngrad, 1972) was desis!ned to carry on a diblogine and thus had to dial with the selection aspect of reference fieneration. The task domain allowed three simplifying, assumptions:

- Nll informatinn known to the fencralor is also known to the listener. Thus, any obyce which needs to be referenced can be referenced by sulecting, sufficient information destengushing it from other objects. Finthermore, any pirce of information which can discrimtmate between oljucts in the robot's model will ellable the listener to perform the same discrimination.

- The number of objects in the world model at any time is sufficiently small thit it is computationaly fessble to determiane whother a description milguely deserthes an object. Thus, it is not meessary to matutain a context, or sutmodel, whthin which to make the discrimtnation.

- The filformation alout each olject is sufficiently small, and sufficiently refiular. thit the selection process cin avoud search. In Mlocksworld, this allownted to sielectinf properties in a fixed order until the accumulated properties umiquely described the object.

Wincerad's program produces both definte and indefinite noun phrases to Iefer to toy blocks. The choice botwen defonite and indefinite is made on the bases of syntactic foutures of the question heills answered. The noun phrase is constructed by concolenating adjectives naming. the block's size and color with a noun naming its shape. In colses where a definite reference ts required and size. shape, and colos are insufficient to uniquely identify the block being referenced. relative clauses can be added which five the block's proper name, if th has one, and Its spatial relationship to other blocks. 
$\Lambda$ fiw discoltse heuristics ill lllocksworld affected the generation of referrinf, cxpressions. Scts of individual blocks were normally referred to by collofinluf: the descriptions of the illdividuals in the set. However, If the drectiptions were identical, which could happen when indefinite descriptions wire used, the entire set was described by prefixillg, its cardinality to a description of one of the elements alld making, the noun plural--"three small cubes." Pronouns would be introduced if the concept being referenced had served as the referent of a "nral by" expression. 


\section{A SYSTEM FOR TIIE SFLECTIVE GENERATION OF REFERRING PHRASES}

In this scction, we will describe a system we have developed that uses the notions described in the previous scctions to tackle some of the problems of drcidinf, how much to say about a given concept. In a typical generation task, we want to express a given concept in service of some particular generation goal. But there is then an 1ssue of how much needs to be said about the concept. It is almost never appropriate to express everything known about the concept. Obviously, the cholce of what to say will depend upon the context within which the referring phrase will exist.

Girice (1975) has specificd at a very general level some of the rules for drcidinf, what to say, in a form called "conversational postulates." Of particular concern for us is his "lostulate of Quantity":

1. Make your contribution as informative as is required (for the current purposes of the exchange).

2. No not makc your contribution more informative than is required. (Grice, 1075, p. 45)

We have implemented a system that, given a particular concept to express and a particular context, creates recommendations of what aspects of the concept to cxpress and what aspects not to express. This system, called CES, represents context as a lublic Workspace, as already described, and contains processes for usfinf the salience of the aclivations in lublic Workspace and the specifications of the current concept.

\section{WIIAT TOSAY}

Consider a particular concept to express. In the movic The Tall Blond Man with One Black Shoc there is a character who is a tall bloud man with one black shoe (and olle brown shoe). Fach tine that we talk ahout this man, we don't want to have to urrution all of these specifications; yet we usually have to mention at least some of them. This is about as far as the l'ostulate of Quantity take us, which isn't far enoug, h to implement a process model of deciding what to say. We have to know in a bit more detail how to deternine what is just enough to say, not too little or too much. 
Suppose the context is sut by the comprehenston of the sentences "The tall hond man with one black shoe was unarmed. lie was chased by the handsome dark haired spy with a foiden finn." Within the framework for reference presented here, this means that the lublic Workspace of the Generator (and, presumably, also the llearer) contains an activation of the blond, with spectfications of tall, blond, min, havinf, one back shoe, and beinf, unarmed, and also an activation of the spy, with speciftcations of handsome, dark haired, spy, and having a golden fun. Suppose that we now want to generate a semence snying that the dark hatred spy slipped. We can't just s.y "lle slipped" lucause "he" doesn't distingutsh between tlic tal! blond and the spy. It would be over'sill to say "Tlie handsome dark hatred spy with the golden fun slipped." $A$ marpillal expression in this context is "The hand some man slipped," since we don't know whether the tall hond is handsome or not. A tetter expression is "The dark haired man slipped." licre we start to see some of the factors determining, the setection process--we want to say at least enough to distinfiush the cencept we wallt to convey from the otliers din Public Workspace. This is natural if we consider the purpose of fenerating the expresston: to "stimu'ate" an activition of this concept tn the workspace of the Hearer. This goal can be achteved only if we supply enough unformation to rule out the other concepts currently "on the tahic" in the conversation.

Consider aunther sentence we inght wallt to generate within this same context. Wr want to say that the syy threatened to shoot the bind. In this case, the comprehender of the verb "shoot" th this sentence can genetate an expectation thint the person shooting has a filli. So it is not necessary to express the specifications that the spy had a gill. Moreover, we cill use this expectation (and any others we have for the posituon in the surface sentence where the phrose will appe,ir) to rule ont posstile ambiguities, even hefore anything is expressed. Thus, in this case, we onty need to rule out the thanimate objects to convey the spy--saying "he" is sufficiont.

In aldition, the first purt of the sentence "lle threatened to shoot..." fincrates expectations for the ollier parameter of "shoot" that uniquely specify that the tall blond is tutended, even before anything is suid. So we need not say allythinf: "lie threatened to shoot." in this way, we can generate ellipsis in coses allowed by syntactic considerations.

Fine Clis System recommends expressing the specifications of the current expresston that rule out any "confusion candidates" in the lublic Workspace. A coufusson candidate is an activation in the public Workspace that is consistent with everything. known so far alout the current expression. This knowledge Includes the expectations about the current position that the hearer could be riasonably expected to share, and the specifications so far recommended for expression. 


\section{Prpectations}

The expectithons atout the current posttion may be feurated by the other linfulpic feneration processes runntng, concurrently with the CES component. For "Nilliple, expectituons call be finerated about the current position from multischtenthal structure processes, like sctipts (Schank \& Alelson, 1975) or the

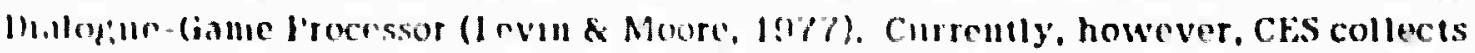
crectations trom ouly two sources. lirst, 1 looks at the predicate of which the current concept is a parameter. III long:-lerm Memory, there may be general informintion known ahout this purameter position which cin then be expected to holl atout the current concept. These expectations, plus those direclly supplled by the callinf, process, form the expectations atout the current position.

\section{(Mider of Selection}

II tlin proces of considerinf, which specifications to express, we clearly uant la silect those that rule ollt at least one of the confusion candidates. However. llwere are many different possible sets of specifications, each of which would rule oilt all the confusion candidates, findmi, the "optumal" (smallest) set would be ditticult, introducinf, a combinatoric explosion problem. For the cFs systent, we hive selected an aproximation to all optumal choice. At cach point in the process. the Clis system silects the specification to expross that rules out the largest number of confuston candidates. This process continues until all confusion candidates are rliminated.

What NOT to say

The Clis syston decides that a spectication need not be expressed for one of two different redens. First of all, we have the expectations about the current postion, described estlicr. Since these are generated from common knowledge, the heiter probahly shores these cxpectitions. so, ally specification of the current concept that is in this expectation set is marked by CtS as not to be expressed, since It would be redundant to expressit.

The other way that Cr.s decides what wot to say occurs bater in the processing of a fiven concept. CHS recommends expressing specifications until all of the confusion candidates are ruled out. 'Those remaining need not be expressed.

Frample

l.' us run throush a quick cxample of how the cFs system operates. Given the context described previously for the tall blond man and the spy. how does CES operate to declde how to express the handsome spy slipping? First, expectations are 
cullecled trom the reneral concept for "slip." If the arent were constrained to be inim.ite, Ct.S will use this constrant as an expcctation on this afent. CF.S now will rule out all inamimate concepts, in this case, the folden fiun and the black shoe. To h.1Hतle the case of expectation violation, as in metaphorical uses of language, if an crpectition rules ollt the concept to be conveyed, CF.S will ifnore the expectation. liut Cl.S still has to cllminate the remaininf confusion candidate, the tall blond IIIn. The specillication of dark-haired is selected, because it explicltly rules out thr bloud man.

In a more complex case, CES will try cach specification to sce how many of thr collfusion sct are rulcd out, and recommend expressing, the one that rules out thr most. This cycle continues unil no more confusion candidates exist, or no more specifications exist.

II some cises, Ct.s will be unatic to rule ont one or more confusion cindldates, even after considering, all known specification of the current concept. Currently, CES fiver up and admits its inntility to wiliquely specify the concept. Fillire dircctions for rescerch may dcal with these problem cases, perhaps by use of "ive reference ("the sccond spy I mentioned"), or the introduction of nonrestrictive specificatlons, 1.c., those In the ncnerator's private Workspace but not in the Public Workspace. 


\section{SUMMARY}

We have presented a framework for reference processing, derived from a taxonomy of the varlous heuristics currently used to comprehend references. Within this general framework, we described a model for selecting what to say (and what not to say) when generating a referring phrase for a concept. The framiework proposes that the various sources of information bearing on reference processing, are inter.rated by having, the scparate processes all producing global cffects on one common Public Workspace. In this way, many different processes can be defined that operate autonomously to contribute information of differing defirees of certainty, which are integrated by the general framework presented hore.

Cur model of referring phrase generation has been partially implemented and trsted on several examples for a siniple data base. We believe that the model cannot he asscssed adequatcly until an implementation has been integrated into a text generation process capable of maintaining the Public Workspace data base across multiple utterances. 


\section{REFERENCES}

1. Archbold, $\Lambda . \Lambda$. 1975. Text reference and repeated propositional reference: Concepts and detection procedures. Unpublished paper, Information Sciences Institute, August 1975.

2. Maranolsky, S. 1970. Some heuristics for automatic detection and resolution of anaphora in discourse. Unpublished master's thesis, University of Texas, 1970.

3. Hobrow, I. G., and T. Winograd 1977. "An overview of KRL, a knowledge representation language," Cognitive Science, 1, 3-46.

1. Chare, W.1. 1972. "Jiscourse structure and human knowledge," in R. O. Frecdle and J. B. Carroll (eds.), Language Comprehension and the Acquisition of Knowledgc. Washington, D.C.: Winston.

5. Collins, A. M., and M. R. Quillian 1972. "How to make a language user," in F. Tulving, and W. Donaldson (eds.), Organization of Memory. New York: Academic I'ress.

6. Inutsch, 13. G. 1974. "The structure of task oriented dialogs," Proceedings of the IFEE Symposium on Specch Recognition, l'ittsburgh, Pa.

7. Goldman, N. 1975. "Conceptual generation," in Schank, R.C. (ed.), Conceptual In formation Processing. New York: American Elsevier.

8. Grice, H. 1'. 1975. "I.ofic and conversation," in P. Cole and J. L. Morgan (cds.), Syntax and Semantics: Spcech Acts, Vol. 3. New York: Academic Press.

!. Hayes, 1. 1977. "On semantic nets, frames, and associations," Proceedings of thr Fifth International Joint Conference on Artificial Intelligence, Cambridge, Mass.

10. I,nvin, J. $\Lambda$. 1976. I'roteus: $\Lambda$ n activation framework for cognitive process modrls. Doctoral dissertation, University of California, San Diego.

11. I,rvin, J. A. 1978. Continuous processing with a discrete memory represcntation. Paper in preparation, Department of Psychology, University of California, San עicgo. 


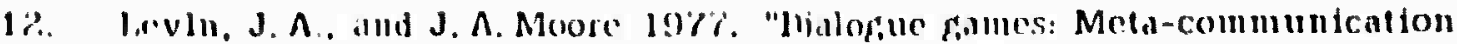

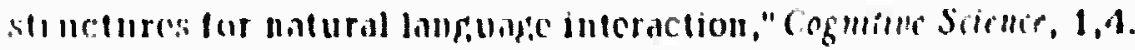

1i1. M.ndler, (i. l!lit. "Association and ongunization: lacts, fancles, and

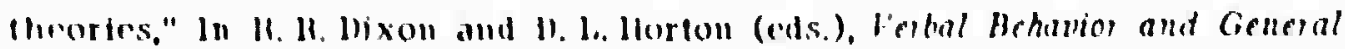
llehwion 7 hem y. Hinglewond Clifis, N.J.i l'rentice-llall.


limils on onr copacity for pocessinf, information," P's vihological Renisu, 63. $111-9 \%$.

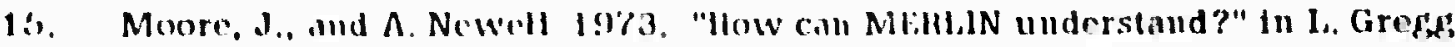

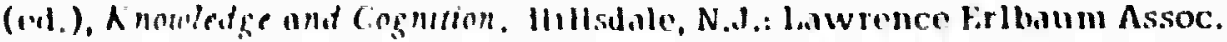

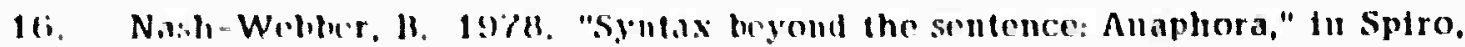

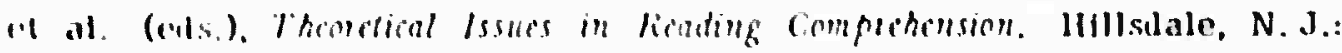
law rence firlhimm $\Lambda$ ssoc. (forthcoming:).

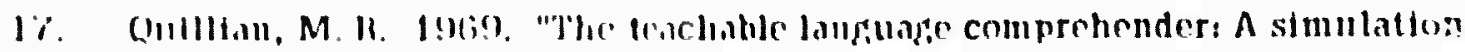

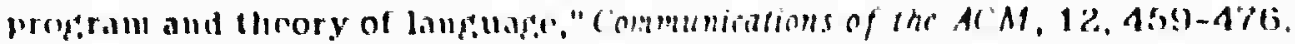

1H, Nirger, C. I!I I. "Concepthal memory and luference," th Schank, R.C. (ed.).

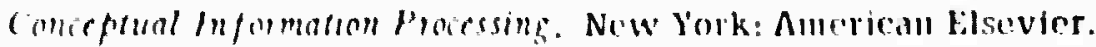

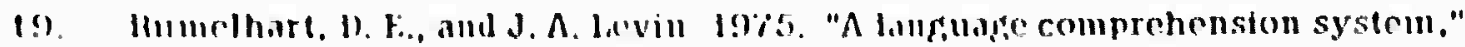



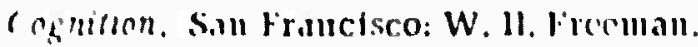

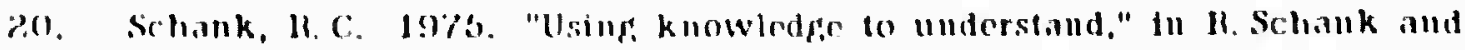
11. 1. Nosh-Webher (ols.). Thronchal lisues in Nolual language Processing. (inillbridgr. M.ıss.: llolt llerallek alld Newin.sn.


rencedtungs of the fourth Intrinational Jeint confolence on Altificial Intelligance, "lbilisi, lissll.

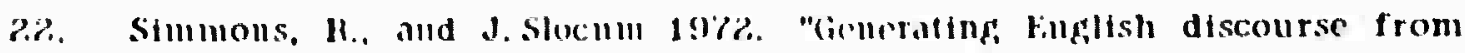
semantic networks," Commumianons of the AC:M, 15,10.

23. Warnock, li.ll. I972. Nunphoric reference: Finding the antecedent. Inpublished paper, llarvard llituersity. Is'r..

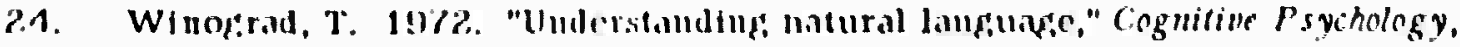
$3,1-191$. 